\title{
Influence of Coolant in Machinability of Titanium Alloy (Ti-6Al-4V)
}

\author{
Nambi Muthukrishnan', Paulo Davim² \\ ${ }^{1}$ Department of Mechanical Engineering, Sri Venkateswara College of Engineering, Sriperumbudur, India; \\ ${ }^{2}$ Department of Mechanical Engineering, Campus Santiago, University of Aveiro, Averio, Portugal. \\ Email: mk@svce.ac.in, pdavim@ua.pt
}

Received February $13^{\text {th }}, 2011$; revised March $15^{\text {th }}, 2011$; accepted March $21^{\text {st }}, 2011$.

\begin{abstract}
Application of titanium alloy has increased many fields since the past 50 years. The major drawback encountered during machining was difficult to cut and the formation of BUE (Built up Edge). This paper presents the tool wear study of TTI 15 ceramic insert (80\% Aluminum oxide and 20\% Titanium carbide) on machining Ti-6Al-4V at moderate speed with and without the application of water soluble servo cut $S$ coolant. Titanium alloy is highly refractory metal and machining titanium is challenging to the manufacturers. Experiments were carried out on medium duty lathe. Application of coolant tends to reduce tool wear and minimize adhesion of the work material on the cutting tool during machining and also improves the surface finish. Result provides some useful information
\end{abstract}

Keywords: Titanium Alloy, Machining, TTI 15 Ceramic Insert, Coolant, Surface, Roughness, Tool Wear

\section{Introduction}

Machinability of a material can be defined and measured as an indication of the ease or difficult with which it can be machined. Machinability of a material may be assessed by tool life, metal removal rate, cutting forces and surface finish $[1,2]$. Titanium alloys are now being constituted in modern aerospace, marine, automotive, atomic power plant reactor, medical instruments and chemical industry due to their strength to weight ratio that can be maintained at elevated temperatures, excellent corrosion and fracture resistance and low modulus of elasticity [3-5]. However, machining of titanium and its alloys can be considered very difficult to cut materials due to its highly chemical reactivity and tendency to weld to the cutting tool, which resulted in edge chipping and rapid tool failure [4]. The advancement in the development of the cutting tools for the past few decades showed little improvement in the machinability of titanium alloys. Most of the cutting tools developed so far, including diamond ceramics and Cubic boron nitride, are highly reactive to titanium alloys, causing rapid wear especially at higher cutting speeds [6-8]. Titanium alloy, Ti-6Al-4V is known to be the workhorse for aerospace and non-aerospace applications. Previous study by [9] indicated that Ti-5Al-4V alloy possessed superior machinability in both drilling and turning tests when com- pared to Ti-6Al-4V.

Studies by [10-12]reported that, when machining titanium alloys, straight tungsten carbide (WC/Co) cutting tools have proved their excellence in almost all processes, except of the tool wear.

According to [4] cutting tool materials used for machining titanium alloys usually have short tool life and most react with the titanium work materials. This disadvantage is due to the generation of high temperatures closer to the cutting edge of the tool. Most of the problems associated with conventional machining of alloys have been dogged by high consumption of cutting tool materials due to excessive tool wear as a result of high-temperature generation at the cutting interfaces.

To over came this drawback, [4] suggested highpressure jet-assisted cooling technology during machining of super alloys is the temperature reduction at the cutting interface due to improved access of coolant closer to the tool cutting edge. This proved significant improvement in tool life because of lower tool wear rates. The main tool failure criteria reported in the literature is rake and flank face wear which resulting from two wear mechanisms: dissolution-diffusion and attrition.

P. A. Dearnley et al. [11] found that ion implantation of chlorine and indium ions in tungsten carbide tools were successful in improving the life of the tools. The 
performance of mixed WC grades has been found to be poorer due to the high diffusion rates of $\mathrm{TiC}$ and $\mathrm{TaC}$, leading to preferential attrition of these carbides from the tool [13].

Emmanuel [14] have investigated the high pressure coolant softens the machining surface by making the interference temperature low.

The aim of this present work is to investigate the influence of water soluble coolant in machining of titanium alloys (Ti-6Al-4V) with and without the application of coolant. The effect of cutting conditions on tool flank wear and surface roughness are also evaluated.

\section{Experimental Procedure}

Work piece samples of $40 \mathrm{~mm}$ diameter bar of $250 \mathrm{~mm}$ length were obtained from Kalpakam atomic power plant, Chennai. Work materials are being used in the power plant reactors. Turning tests were carried out on work material using water-soluble oil designated as Servo cut $\mathrm{S}$ lubricant oil. It forms a milky emulsion with water and contains rust inhibitor to impart anti-rust, anti-corrosion properties and a biocide to prevent bacterial growth in the emulsion. It has superior cooling and lubricating properties which impart excellent surface finish and minimizes tool wear. It is used in different concentration based on the type of operation. From open literature, to obtain best performance, stable emulsion oil should be added to 75\% water. It meets BIS: 11151986 specification and is recommended for a variety of cutting operations on ferrous and non-ferrous metals.

All the tests were carried out on medium duty lathe with $2 \mathrm{~kW}$ spindle power. Cutting inserts used were DNMG 120408, TTI 15 ceramic insert with top rake angle of 0 degree. It has density of $4.2 \mathrm{~g} / \mathrm{cm}^{3}$, Vickers's hardness 2200 , and toughness $4 \mathrm{MN} / \mathrm{m}^{2 / 3}$.It is suitable for high speed cutting due to superior hardness at high temperature, low chemical affinity to workpiece gives better finish and machining accuracy, high wear resistance and ensures longer tool life. Tool holder used was PCLNR $25 \times 25 \mathrm{M} 12$ Chemical composition is shown in Table 1. Mechanical properties are shown in Table 2. Figure 1 shows the experimental set up with work material Titanium Alloy (Ti-6Al-4V).

Experimental investigations were carried out on the work material with TTI 15 ceramic insert. Table 3 summarizes the experimental conditions and Table 4 shows the tool specifications of TTI 15 ceramic insert. Experiments were conducted and analyzed the machining parameters and graphs were drawn. Out of this, the best trial was investigated with the help of surface integrity.

The best trial was found as Cutting speed $135 \mathrm{~m} / \mathrm{min}$, feed $0.10 \mathrm{~mm} / \mathrm{rev}$ and depth of cut $0.5 \mathrm{~mm}$. using this parameter tool wear study was performed for time dura-
Table 1. Chemical composition of work material.

\begin{tabular}{cccccc}
\hline Alloy & $\mathrm{Al}$ & $\mathrm{V}$ & $\mathrm{Fe}$ & $\mathrm{C}$ & $\mathrm{Ti}$ \\
\hline Ti-6Al-4V & $6.40 \%$ & $3.89 \%$ & $0.16 \%$ & $0.002 \%$ & Balance \\
\hline
\end{tabular}

Compositions are given in $\%$ by weight

Table 2. Mechanical Properties of Ti-6Al-4V.

\begin{tabular}{cc}
\hline Hardness (HRA) & 70 \\
\hline Hardness Knoop & 363 \\
Tensile strength, Ultimate & $950 \mathrm{MPa}$ \\
Elongaion & $14 \%$ \\
Poisson's ratio & 0.342 \\
Modulus of Elasticity & $113 \mathrm{GPa}$ \\
Density & $4.43 \mathrm{~g} / \mathrm{cm}^{3}$ \\
\hline
\end{tabular}

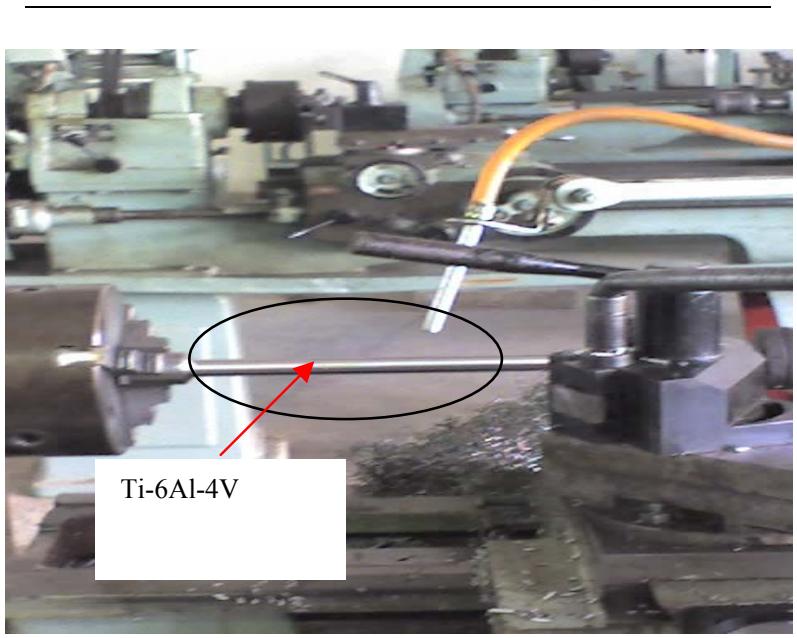

Figure 1. Experimental set up with Titanium alloy.

Table 3. Experimental conditions.

\begin{tabular}{cc}
\hline Cutting speed & 45,90 and $135 \mathrm{~m} / \mathrm{min}$ \\
\hline Feed & $0.10,0.20$ and $0.32 \mathrm{~mm} / \mathrm{rev}$ \\
Depth of Cut & 0.5 and $0.75 \mathrm{~mm}$ \\
Cutting condition & With and without coolant \\
Machine & Medium duty lathe \\
\hline
\end{tabular}

Table 4. Tool specification of TTI 15 ceramic insert.

\begin{tabular}{ll}
\hline Composition & $80 \% \mathrm{Al}_{2} \mathrm{O}_{3}$ and $20 \% \mathrm{TiC}$ \\
\hline Grain Size & $3.0 \mu \mathrm{m}$ \\
Transverse Rupture Strength & $551-786 \mathrm{MPa}$ \\
Average density & $3.90-3.99 \mathrm{~g} / \mathrm{cm}^{3}$ \\
Youngs Modulus & $641 \mathrm{GPa}$ \\
Hardness & $91-94 \mathrm{HRA}$ \\
Coefficient of Thermal expansion & Good \\
\hline
\end{tabular}

tion of 45 minutes.

Average surface roughness (Ra) was measured with the help of surface roughness tester (Model : Mitutoyo $301)$ with the cut-off $0.8 \mathrm{~mm}$, Tool flank wear $\left(\mathrm{V}_{\mathrm{Bmax}}=\right.$ $0.4 \mathrm{~mm}$ ) as per ISO 3685:1993 was measured with the 
help of toolmakers microscope. Wear images were captured by Scanning Electron Microscope (SEM) and Optical microscope. Table 5 shows the experimental readings

\section{Results and Discussions}

\subsection{Surface Roughness}

Figure 2(a) shows the influence of cutting speed on machined surface obtained while machining Ti-6Al-4V with coolant (wet machining) and Figure 2(b) shows the same graph without coolant (Dry machining). In general surface roughness of machined component decreased with the increase in cutting speed. It may be suggested that adherence of the work piece material to the tool at higher cutting speeds are less pronounced, perhaps due to the high temperature generated [5]

Surface roughness obtained was very good with coolant compared with dry machining. Similar trend was observed for other depth of cut also for dry and wet machining (Figures 3(a,b)). In both machining, surface roughness decreases as cutting speed increases. In dry machining, due to formation of Built-up-Edge (BUE), machined surface gets damaged by insert dragging over the surface of machined component with BUE $[4,5]$. In wet machining the coolant prevents the formation of BUE and also reduced the heat generated in the interface.

Figures 3(a,b) shows the influence of coolant on machining the workpiece with ceramic insert. From Figure 3 , it is clearly understood that, surface roughness decrease with increasing the cutting speed. It is obvious that, ceramic insert has high hardness at high temperature. Analysis on surface roughness proved that an increase in feed rate produced a general trend towards higher surface roughness [15] the machined surfaces consist of uniform feed marks in perpendicular to the tool feed direction. Surface damages are also observed after machining. Some feed marks also observed, this is attributed by plastic flow of material during the cutting process. Plastic flow of material on machined surfaces results in higher surface roughness values [16].

Generally surface finish of the machined component is good, with TTI 15 ceramic insert under wet machining. In $0.75 \mathrm{~mm}$ depth of cut surface roughness is slightly higher at higher cutting speeds, because of influence of depth of cut on surface finish. In TTI 15 ceramic insert, surface roughness gradually decreases from maximum to minimum, because of formation of BUE, which affects the surface quality of the machined component at lower cutting speeds; at higher cutting speeds formation of BUE is not noticed. As a result good surface finish is obtained. It is suggested to machine the Titanium alloy under wet machining which soften the machined surfaces under coolant. It makes the interface to efficient cooling by coolant to get optimum life [14]

\subsection{Effect of Feed Rate}

Figures $4(a, b)$ show the effect of feed rate on average surface roughness on machining Ti-6Al-4V alloy with coolant for depth of cut $0.5 \mathrm{~mm}$ and $0.75 \mathrm{~mm}$ respectively. It is observed that, feed rate has more influence on surface finish. It increases from minimum to maximum. Good surface finish is obtained at higher cutting speed with low feed rate. At higher cutting speed tool wear is more. Confirming that cutting speed has the largest influence on tool wear/tool life, as commonly reported $[7,15]$

Table 5. Experimental data.

\begin{tabular}{|c|c|c|c|c|c|}
\hline Expt. $\mathrm{N}^{\mathrm{o}}$ & $\begin{array}{l}\text { Cutting Speed } \\
(\mathrm{m} / \mathrm{min})\end{array}$ & $\begin{array}{l}\text { Feed Rate } \\
(\mathrm{mm} / \mathrm{rev})\end{array}$ & $\begin{array}{l}\text { Depth of Cut } \\
(\mathrm{mm})\end{array}$ & $\begin{array}{c}\text { Average Surface Roughness }(\mu \mathrm{m}) \\
\text { With Coolant* }\end{array}$ & $\begin{array}{c}\text { Average Surface Rough- } \\
\text { ness }(\mu \mathrm{m}) \\
\text { Without Coolant* }\end{array}$ \\
\hline 1 & 45 & 0.1 & 0.5 & 1.30 & 1.75 \\
\hline 2 & 90 & 0.1 & 0.5 & 1.15 & 1.65 \\
\hline 3 & 135 & 0.1 & 0.5 & 0.80 & 1.20 \\
\hline 4 & 45 & 0.2 & 0.5 & 2.80 & 3.00 \\
\hline 5 & 90 & 0.2 & 0.5 & 2.35 & 2.50 \\
\hline 6 & 135 & 0.2 & 0.5 & 1.90 & 2.20 \\
\hline 7 & 45 & 0.32 & 0.5 & 4.60 & 5.05 \\
\hline 8 & 90 & 0.32 & 0.5 & 4.50 & 4.85 \\
\hline 9 & 135 & 0.32 & 0.5 & 4.15 & 4.45 \\
\hline 10 & 45 & 0.1 & 0.75 & 1.60 & 1.75 \\
\hline 11 & 90 & 0.1 & 0.75 & 1.30 & 1.55 \\
\hline 12 & 135 & 0.1 & 0.75 & 1.00 & 1.15 \\
\hline 13 & 45 & 0.2 & 0.75 & 2.70 & 3.15 \\
\hline 14 & 90 & 0.2 & 0.75 & 2.55 & 2.65 \\
\hline 15 & 135 & 0.2 & 0.75 & 2.20 & 2.45 \\
\hline 16 & 45 & 0.32 & 0.75 & 5.15 & 5.25 \\
\hline 17 & 90 & 0.32 & 0.75 & 4.75 & 4.55 \\
\hline 18 & 135 & 0.32 & 0.75 & 4.15 & 4.25 \\
\hline
\end{tabular}

Average of three repetitions 


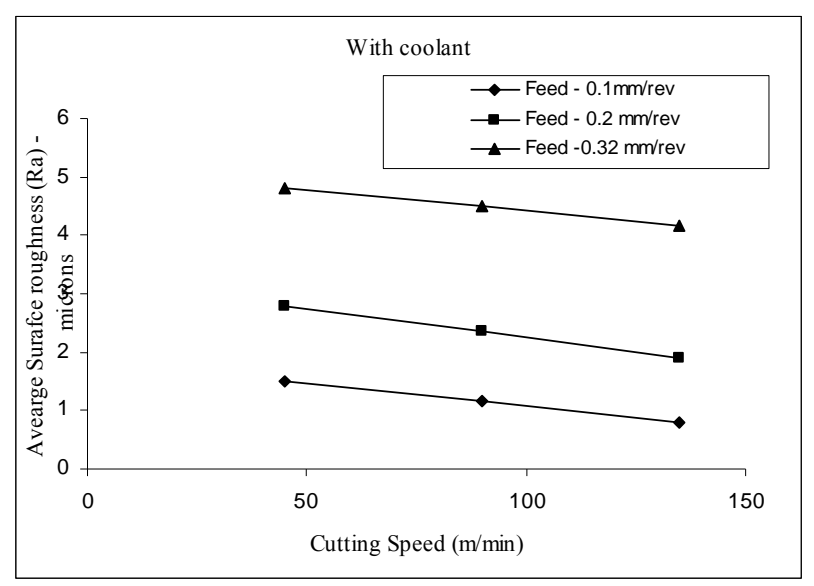

(a)

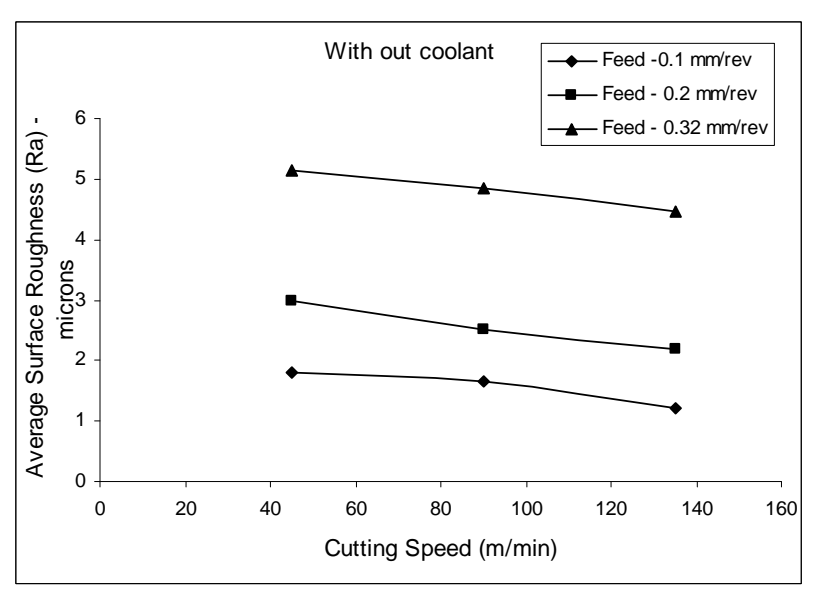

(b)

Figure 2. (a,b) Surface roughness (Ra) Vs Cutting Speed (depth of cut $-0.5 \mathrm{~mm}$ ).

Similar trend exists for other machining condition (wet machining). Surface roughness values are lesser than that of dry machining under similar machining parameters. This is happened due to the presence of coolant in theinterface which reduces the heat generation and avoids the adhesion nature of the work material.

\subsection{Tool Wear}

Main cause of the tool wear mechanism in machining Ti-6Al-4V was found to be diffusion, due to high temperature in the interface. Adhesive and attritution wear also take place due to micro hardening of the material [14]. From Figure 5, it was observed that tool flank portion in TTI 15 ceramic insert is subjected to uniform wear under wet machining. This could be reduced by high pressure jet assisted cooling in the tool interface in order to reduce the temperature [4]. The wear in TTI 15 insert attained only $0.1 \mathrm{~mm}$ after 45 -minute duration.

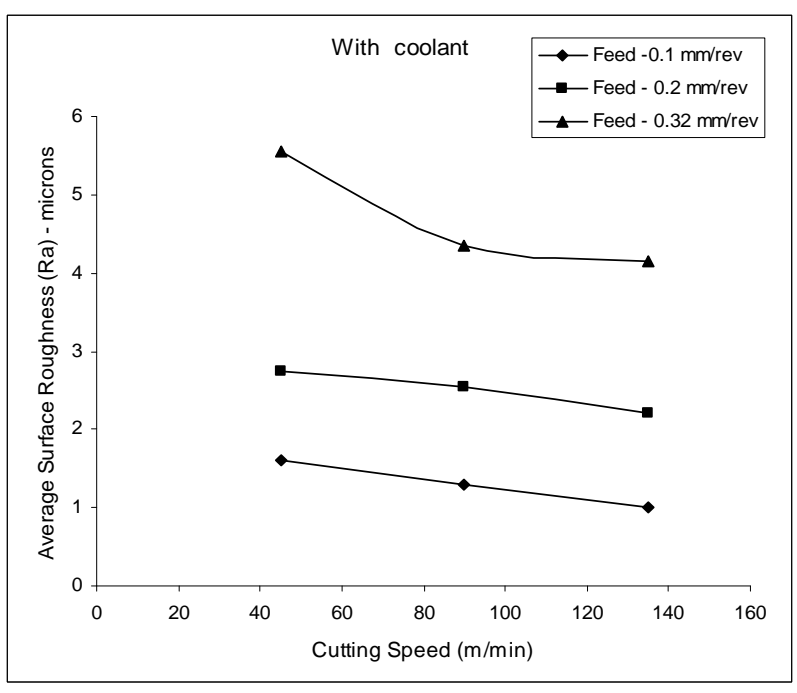

(a)

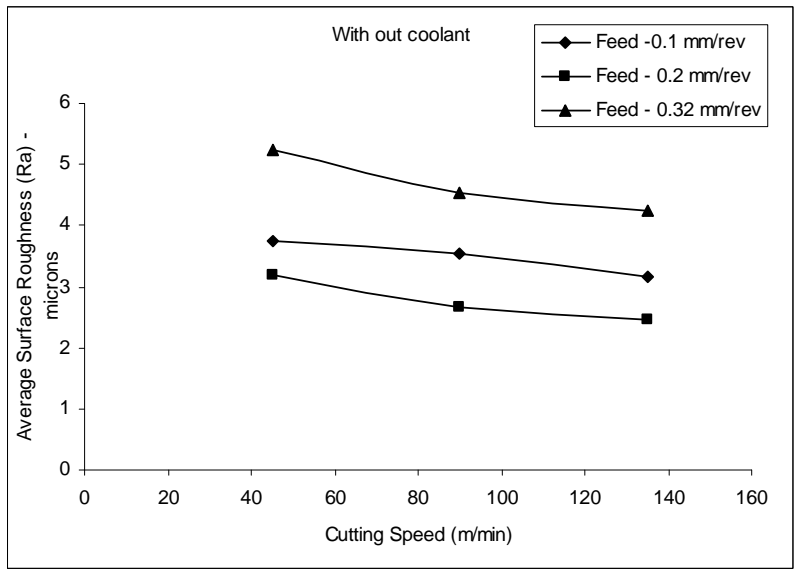

(b)

Figure 3. (a,b) Surface roughness Vs Cutting Speed (Depth of cut $-0.75 \mathrm{~mm}$ ).

Tool wear is less at TTI 15 ceramic insert at the beginning. It was observed that uniform diffusion/adhesive wear is existing in the flank portion for the first $15 \mathrm{~min}$ utes duration, After that, it was noticed that, sudden in-crease in the wear, this is happened due to shock loading associated with the machine and micro chipping of the insert was found at the nose region. Figure 6, shows the rake and flank portion of TTI 15 ceramic insert. In Figure 7, built up edges are seen on the flank portion of the insert. It was also one of the reasons for tool wear [15].

When machining with TTI15 ceramic insert, there was as increase in the hardness of the surface of Ti-6Al-4V. This hardness may also believe to increase the adhesive wear [17].

When machining with dry condition, it was observed that tool diffusion/Adhesion wear is not uniform. There was a sudden increase in the wear, because of the heat 


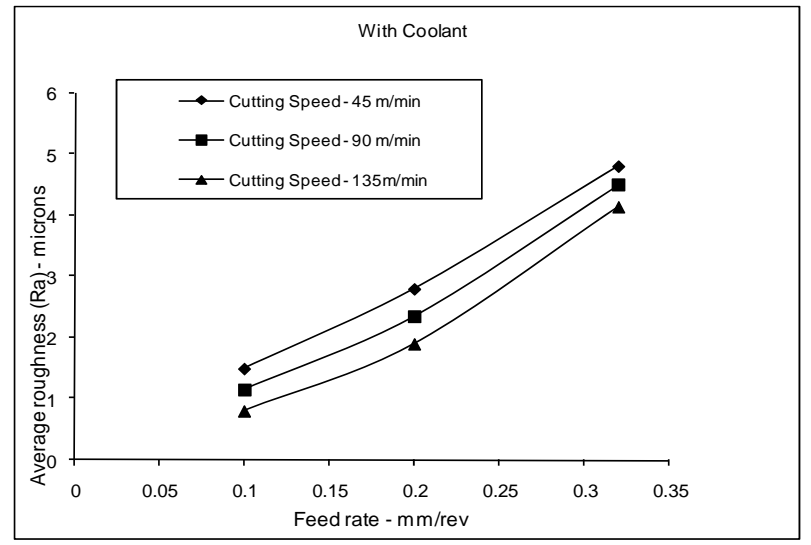

(a)

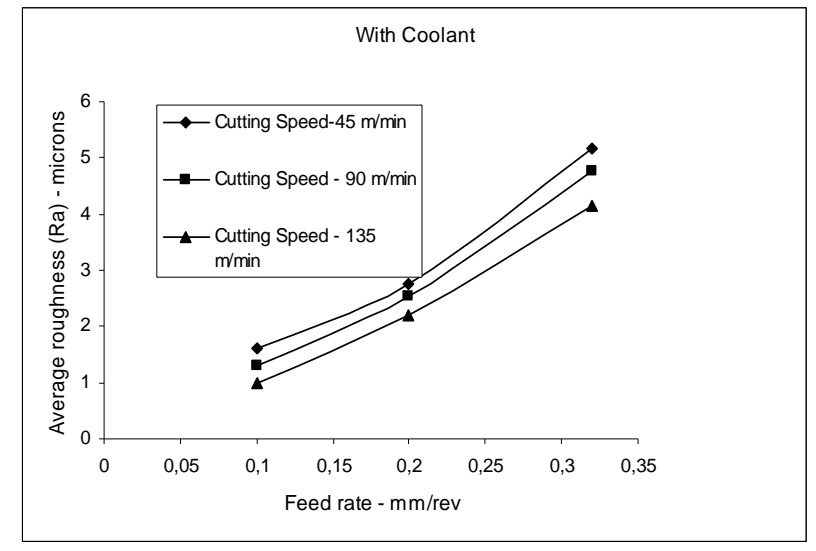

(b)

Figure 4. (a,b) Effect of feed rate on surface roughness.

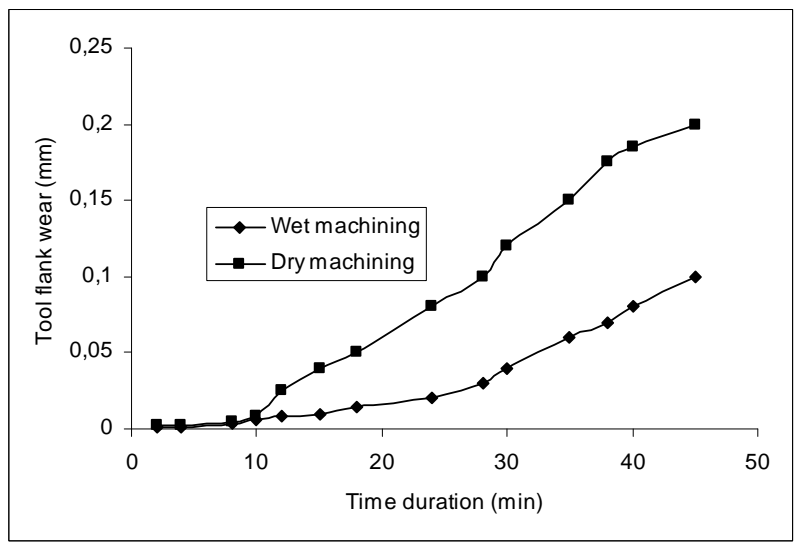

Figure 5. Tool wear versus machining time.

generated in the interference zone was critical [10] The sharp cutting edge in the insert became blunt and BUE formation was more at the cutting edge because of the adhesion. At the end of 45 minute duration, tool wear on the insert under dry machining is approximately $100 \%$ more than that of the insert under wet machining.

\section{Conclusions}

The following conclusions are drawn, when machining Ti-6Al-4V with TTI 15 ceramic insert at various cutting speeds are as follows

1) Machining with coolant gives good surface finish compared with dry machining.

2) Tool wear is less for TTI 15 ceramic insert under the selected cutting conditions under wet machining.

3) Tool life is improved by $30 \%$ when machining with coolant.

4) Diffusion /adhesive wear is in the flank portion which was the dominant tool wear for TTI 15 ceramic insert.

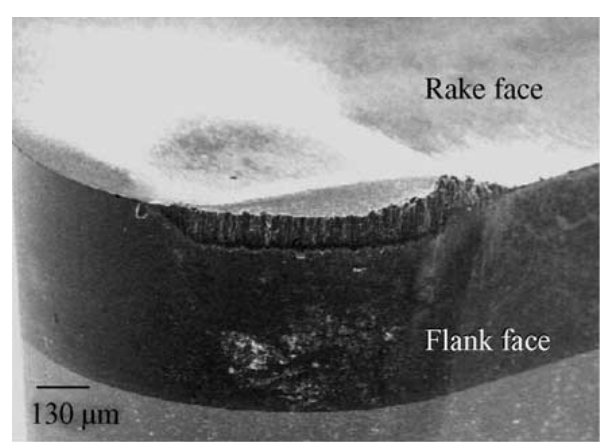

Figure 6. Tool wear with coolant.

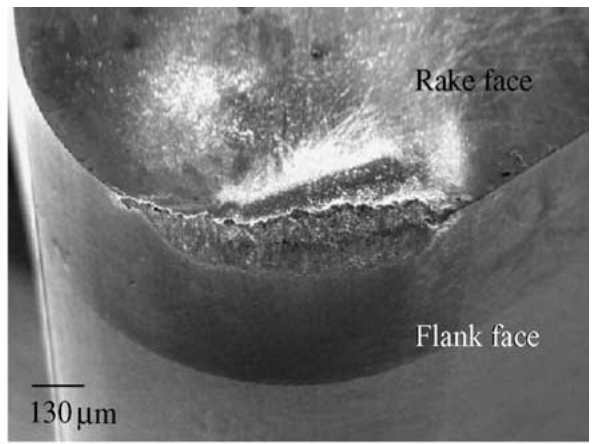

Figure 7. Tool wear without coolant.

5) Surface finish improves generally, with increase in cutting speed with and without coolant

6) Adhesive wear is observed at the flank portion of the insert on both dry and wet machining. Diffusion wear is more in dry machining

7) Attritution wear also presented in the insert.

\section{REFERENCES}

[1] E. M. Trent, "Metal Cutting," Butterworth-Heinemann, 
Oxford, 1991.

[2] E. M. Trent and P. K. Wright, "Metal Cutting," 3rd Edition, Butterworth Heinemann, Boston, 2000.

[3] W. Koning, "Applied Research on the Mach Inability of Titanium and Its Alloys," Proceedings of the 47th Meeting of AGARD, London, September 1978, pp 1-10.

[4] A. R. Machado and J. Wallbank, "Machining of Titanium and Its Alloys: A Review," Proceedings'of the Institution of Mechanical Engineers Part B: Management and Engineering Manufacture, Vol. 204, No. 11, 2005, pp. 53-60.

[5] E. O. Augur and Z. M. Wang, "Titanium Alloys and Their Machinability-A Review," Journal of Material Processing Technology, Vol. 68, No. 3, 1997, pp. 262-274.

[6] R. Komanduri and B. F. Von Turkovich, "New Observations on the Mechanisms of Chip Formation When Machining Titanium Alloys," Wear, Vol. 69, No. 2, 1981, pp. 179-188. doi:10.1016/0043-1648(81)90242-8

[7] P. D. Hartung and B. M. Kramer, "Tool Wear in Titanium Machining," CIRP Annals-Manufacturing Technology, Vol. 31, No. 1, 1982, pp. 75-80.

[8] N. Narutaki, A. Murakoshi, S. Motonishi and H. Takeyama, "Study on Machining Titanium Alloys," CIRP Annals-Manufacturing Technology, Vol. 32, No. 1, 1982, pp. 65-69.

[9] Y. Kosaler, J. C. Fanning and S. P. Fox, "Development of Low Cost High Strength Alpha/Beta Tiatanium Alloy with Superior Machinability," $10^{\text {th }}$ World Conference on Titanium, Hamburg, July 2003, pp. 3028-3034.

[10] P. A. Dearnley and A. N. Grearson, "Evaluation of Principal Wear Mechanisms of Cemented Carbides and Ceramics Used for Machining Titanium Alloy IMI 318,"
Materials Science and Technology, Vol. 2, 1987, pp. 47-58.

[11] P. A. Dearnley, A. N. Grearson and J. Aucote, "Wear Mechanisms of Cemented Carbides and Ceramics Used for Machining Titanium Alloys," High-Tech Ceramics, Vol. 38, 1987, pp. 2699-2712.

[12] Z. M. Wang and E. O. Ezugwu, "Performance of PVD Coated Carbide Tool When Machining Ti-6Al-4V," Tribology Transactions, 1997, Vol. 40, pp. 81-86. doi:10.1080/10402009708983632

[13] X. Yang and C. R. Liu, "Machining Titanium and Its Alloys," Machining Science and Technology, Vol. 3, No. 1, 1999, pp. 107-139. doi:10.1080/10940349908945686

[14] E. O. Ezugwu, J. Bonneya, R. B. O. C da Silvab and O. Çakir, "Surface Integrity of Finished Turned Ti-6Al-4V Alloy with PCD Tools Using Conventional and High Pressure Coolant Supplies," International Journal of Machine Tools \& Manufacture, Vol. 47, No. , 2007, pp. 884-891.

[15] J. F. Kahles, D. Eylon, F. H. Froes and M. Field, "Machining of Titanium Alloys," Journal of Metals, Vol. 37, No. 4, 1985, pp. 27-35.

[16] L. Zhou, J. Shimizu, A. Muroya and H. Eda, "Material Removal Mechanism beyond Plastic Wave Propagation Rate," Precision Engineering, Vol. 27, No. 2, 2003, pp. 109-116. doi:10.1016/S0141-6359(02)00124-1

[17] J. I. Hughes, A. R. C. Sharman and K. Ridgway, "The Effect of Cutting Tool Material and Edge Geometry on Tool Life and Workpiece Surface Integrity," Proceedings of the Institution of Mechanical Engineers, Part B: Journal of Engineering Manufacture, Vol. 220, No. 2, 2006, pp. 93-107. doi:10.1243/095440506X78192 